\title{
Pouch Perforation After Augmentation Cystoplasty With Ileocolic Pouch: Report of a Case
}

\author{
Ru-Da Lee ${ }^{a}$, Seung-Hyun Lee ${ }^{\mathrm{a}, \mathrm{c}}$, Byung-Kwon Ahn", \\ Sung-Uhn Baek ${ }^{\mathrm{a}}$, Bong-Kwon Chun ${ }^{\mathrm{b}}$
}

\begin{abstract}
Pouch perforation after augmentation cystoplasty with an ileocolic pouch is an uncommon but life-threatening complication, which can result in peritonitis, sepsis and even death. We encountered a rare case of late pouch perforation after augmentation cystoplasty with an ileocolic pouch. A 52-year-old female was admitted with a chief complaint of acute abdominal pain for the past two days. Twenty years prior, she had undergone left nephrectomy and augmentation cystoplasty with an ileocolic pouch due to left renal abscess. The patient was diagnosed 16 years previously with chronic renal failure, which had been managed with hemodialysis. Physical examination revealed peritonitis with diffuse abdominal tenderness and board-like rigidity. The patient underwent an emergent laparotomy, revealing a perforation of the ileocolic pouch of the bladder, which was filled with stool-like mucoid material. Pouch excision with total cystectomy was performed, but the patient died the next day.
\end{abstract}

Keywords: Urinary bladder; Postoperative complication; Perforation

\section{Introduction}

Augmentation cystoplasty is commonly used for patients with abnormally small bladders or with bladder loss resulting from various conditions $[1,2]$. Common complications of augmentation cystoplasty include difficulty with catheterization, recurrent urinary tract infection and calculi [3]. Blad-

\footnotetext{
Manuscript accepted for publication April 4, 2012

${ }^{a}$ Department of Surgery, Department of Pathology, Kosin University College of Medicine, Busan, South Korea

${ }^{b}$ Department of Pathology, Kosin University College of Medicine, Busan, South Korea

${ }^{\mathrm{c} C}$ Corresponding author: Seung-Hyun Lee, Department of Surgery, Kosin University Gospel Hospital, 34 Amnam-dong, Seo-gu, Busan 602-702, South Korea. Email: gscrslsh@hanmail.net
}

doi:10.4021/jmc636w der perforation is an uncommon complication that results in fatal outcomes [4-7]. Although a definitive etiology is not known, several mechanisms, such as traumatic catheterization, chronic infection, ischemic necrosis of the intestinal segment, and increased intravesical pressure, are postulated [5-10]. While it has been reported that perforations within the first postoperative year sometimes occur along the lines of the surgical anastomosis, the augmenting bowel segments appear to be more susceptible to delayed perforations [7].

Here we present the case of a patient with late pouch perforation after augmentation cystoplasty with an ileocolic pouch.

\section{Case Report}

A 52-year-old female patient presented to the emergency department with a chief complaint of abrupt-onset abdominal pain lasting for the previous two days. Twenty years earlier, she underwent left nephrectomy and augmentation cystoplasty with an ileocolic pouch due to left renal abscess. She was diagnosed with chronic renal failure 16 years prior, and had been managed with hemodialysis. She had not used her urinary bladder for voiding for several years. She had been taking medicines for six months to treat a gastric ulcer.

The patient visited a local emergency department after the acute onset of abdominal pain. She was transferred to our institution under suspicion of peritonitis due to gastric perforation. At admission, the patient was in mild distress but alert and oriented. Her vital signs were normal with blood pressure at $80 / 40 \mathrm{mmHg}$, a pulse rate of 133 beats $/ \mathrm{min}$, a respiration rate of $21 / \mathrm{min}$, and a body temperature of $36.3^{\circ} \mathrm{C}$. On physical examination, she had severe abdominal tenderness and board-like rigidity of the whole abdominal region. Intestinal sounds were audible but weak and with decreased frequency. Laboratory investigations revealed the following: hemoglobin, $15.0 \mathrm{~g} / \mathrm{dl}$; hematocrit, $46.4 \%$; white blood cell count, 2,800 $/ \mathrm{mm}^{3}$ (neutrophil, 36\%); platelet count, $175 \mathrm{x}$ $10^{3} / \mathrm{mm}^{3}$; serum protein, $6.8 \mathrm{~g} / \mathrm{dl}$; serum albumin $3.1 \mathrm{~g} / \mathrm{dl}$; total bilirubin, $1.1 \mathrm{mg} / \mathrm{dl}$; alanine aminotranferase $44 \mathrm{IU} / \mathrm{l}$; aspartate aminotransferase, $21 \mathrm{IU} / \mathrm{l}$; creatinine, $6.9 \mathrm{mg} / \mathrm{dl}$; serum $\mathrm{Na}, 131 \mathrm{meq} / \mathrm{l}$, and serum K, $5.2 \mathrm{meq} / \mathrm{l}$. 


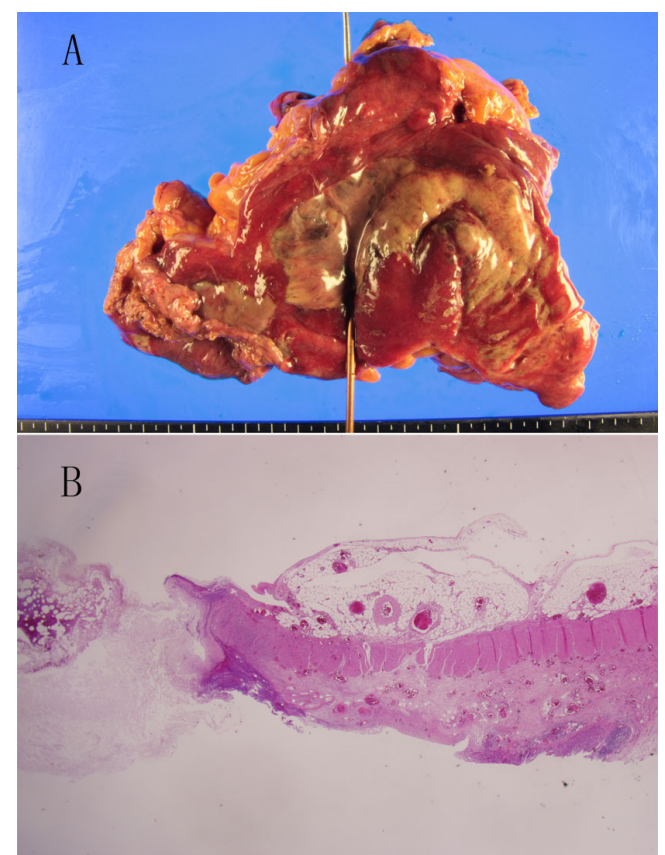

Figure 1. Specimen showed a perforation opening with surrounding ischemic necrosis of the bladder. The necrotic area was ill-defined geographic pale greenish and had a very thin wall (A). Microscopic finding showed a discontinuation of colonic whole layer (black arrow, H\&E stain, x 40) (B).

On laparotomy, a large volume of turbid fluid with a foul odor was found throughout the entire abdominal cavity. There was no remarkable finding in the stomach or duodenum. A perforation of the ileocolic pouch of the bladder was identified (Fig. 1A, B), and gray, stool-like mucoid material was spilling out from the ileocolic pouch. Pouch excision with total cystectomy was performed, but the patient died the next day.

\section{Discussion}

Perforation of the augmented bladder has been reported to occur in $5-13 \%$ of procedures. $[1,7,11,12]$. This complication can result in a fatal outcome with a mortality rate of 25\% [4-7]. Although a definitive etiology is not known, several mechanisms, such as traumatic catheterization, chronic infection, ischemic necrosis of the intestinal segment and increased intravesical pressure, are postulated [5-10]. Approximately one third of augmented bladders perforate within two years of surgery $[2,12]$. While it has been reported that perforations within the first postoperative year sometimes occur along the lines of the surgical anastomosis, the augmenting bowel segments appear to be more susceptible to delayed perforation [7]. The present case had an interval of 20 years between the augmentation procedure and the perforation. The site of perforation was the ileocolic pouch of the aug- mented bladder.

The choice of bowel segment, such as the stomach, the ileum and the sigmoid colon, used for augmentation cystoplasty may contribute to the risk of bladder perforation. DeFoor et al. reported that the perforation rate of ileocystoplasty patients was significantly higher than that in patients who underwent gastroplasty [1]. Metcalfe et al. reported an increased risk of perforation in patients for whom the sigmoid colon was used as an augmenting pouch [2]. High bladder pressure, detrusor hyperreflexia, increased bladder outlet resistance, and bladder overdistension may be risk factors for perforation. Elevated wall tension in the bowel segment or the bladder can lead to ischemic necrosis and perforation. In the present case, the patient had a history of chronic renal failure that had been managed with hemodialysis for the past 16 years. The bladder was not distended with urine but filled instead with gray mucoid content. E. coli was cultured from the peritoneal fluid. Bladder overdistention or chronic infection induced by the mucoid content was suspected to have contributed to the perforation with ischemic necrosis. Periodic bladder irrigation in similar patients may prevent collection of mucoid material in the bladder.

The typical presentations of perforation are suddenonset abdominal pain, distension, rebound tenderness with rigidity, oliguria, or anuria. Nausea, vomiting, fever, septic shock, and respiratory distress may also be present. Some patients present with referred shoulder pain. Abdominal and pelvic computed tomography (CT) with a cystogram is diagnostic with urinary-fluid extravasation. Delayed diagnosis may result in a fatal outcome. Immediate bladder decompression, blood and urine cultures, broad-spectrum antibiotics, and surgical repair are required. Although some stable patients have been successfully managed non-operatively $[13,14]$, it should be emphasized that the standard therapy is surgical exploration. However, in this case, we misdiagnosed the condition as peritonitis with gastric ulcer perforation because the patient had been taking medicines for a gastric ulcer six months prior to admission. Preoperative CT showed an intra-abdominal free air shadow. Urine spillage was not identified. The patient had chronic renal failure and a nonfunctioning bladder. Unfortunately, the overwhelming septic shock was not improved postoperatively, which resulted in death.

Pouch perforation after augmentation cystoplasty is a fatal complication that is not encountered frequently. Perforation should be suspected in patients with abdominal pain who have undergone augmentation cystoplasty in the past, and these patients must be immediately stabilized, evaluated and managed to ensure a favorable outcome.

\section{References}

1. DeFoor W, Tackett L, Minevich E, Wacksman J, Sheldon 
C. Risk factors for spontaneous bladder perforation after augmentation cystoplasty. Urology. 2003;62(4):737-741.

2. Metcalfe PD, Casale AJ, Kaefer MA, Misseri R, Dussinger AM, Meldrum KK, Cain MP, et al. Spontaneous bladder perforations: a report of 500 augmentations in children and analysis of risk. J Urol. 2006;175(4):14661470; discussion 1470-1461.

3. DeFoor WR, Heshmat S, Minevich E, Reddy P, Koyle $\mathrm{M}$, Sheldon C. Long-term outcomes of the neobladder in pediatric continent urinary reconstruction. J Urol. 2009;181(6):2689-2693; discussion 2693-2684.

4. Sheiner JR, Kaplan GW. Spontaneous bladder rupture following enterocystoplasty. J Urol. 1988;140(5 Pt 2):1157-1158.

5. Elder JS, Snyder HM, Hulbert WC, Duckett JW. Perforation of the augmented bladder in patients undergoing clean intermittent catheterization. J Urol. 1988;140(5 Pt 2):1159-1162.

6. Rushton HG, Woodard JR, Parrott TS, Jeffs RD, Gearhart JP. Delayed bladder rupture after augmentation enterocystoplasty. J Urol. 1988;140(2):344-346.

7. Bauer SB, Hendren WH, Kozakewich H, Maloney S, Colodny AH, Mandell J, Retik AB. Perforation of the augmented bladder. J Urol. 1992;148(2 Pt 2):699-703.

8. Anderson PA, Rickwood AM. Detrusor hyper-reflexia as a factor in spontaneous perforation of augmentation cystoplasty for neuropathic bladder. $\mathrm{Br} \mathrm{J}$ Urol. 1991;67(2):210-212.

9. Crane JM, Scherz HS, Billman GF, Kaplan GW. Ischemic necrosis: a hypothesis to explain the pathogenesis of spontaneously ruptured enterocystoplasty. J Urol. 1991;146(1):141-144.

10. Rosen MA, Light JK. Spontaneous bladder rupture following augmentation enterocystoplasty. J Urol. 1991;146(5):1232-1234.

11. Flood HD, Malhotra SJ, O'Connell HE, Ritchey MJ, Bloom DA, McGuire EJ. Long-term results and complications using augmentation cystoplasty in reconstructive urology. Neurourol Urodyn. 1995;14(4):297-309.

12. Shekarriz B, Upadhyay J, Demirbilek S, Barthold JS, Gonzalez R. Surgical complications of bladder augmentation: comparison between various enterocystoplasties in 133 patients. Urology. 2000;55(1):123-128.

13. Slaton JW, Kropp KA. Conservative management of suspected bladder rupture after augmentation enterocystoplasty. J Urol. 1994;152(2 Pt 2):713-715.

14. Leyland JW, Masters JG. Conservative management of an intraperitoneal rupture of an augmentation cystoplasty and continent urinary diversion in an adult. J Urol. 2003;170(2 Pt 1):524. 